\title{
Poxvirus-based vaccine therapy for patients with advanced
} pancreatic cancer

\author{
Howard L Kaufman*1, Seunghee Kim-Schulze1, Kelledy Manson², \\ Gail DeRaffele ${ }^{1}$, Josephine Mitcham ${ }^{1}$, Kang Seok Seo ${ }^{1}$, Dae Won Kim ${ }^{1}$ and \\ John Marshall ${ }^{2}$
}

\begin{abstract}
Address: ${ }^{1}$ The Tumor Immunology Laboratory, Division of Surgical Oncology, Columbia University, New York, NY, USA and ${ }^{2}$ The Lombardi Cancer Center, Georgetown University Medical Center, Washington, DC, USA

Email: Howard L Kaufman* - hlk2003@columbia.edu; Seunghee Kim-Schulze - sk2254@columbia.edu; Kelledy Manson - yd2017@columbia.edu; Gail DeRaffele - gd2023@columbia.edu; Josephine Mitcham - jm2124@columbia.edu; Kang Seok Seo - qw2109@columbia.edu; Dae Won Kim - dwk2104@columbia.edu; John Marshall - marshalj@georgetown.edu

* Corresponding author
\end{abstract}

Journal of Translational Medicine 2007, 5:60 doi:10.1 I86/1479-5876-5-60

This article is available from: http://www.translational-medicine.com/content/5/I/60

(c) 2007 Kaufman et al; licensee BioMed Central Ltd.

This is an Open Access article distributed under the terms of the Creative Commons Attribution License (http://creativecommons.org/licenses/by/2.0), which permits unrestricted use, distribution, and reproduction in any medium, provided the original work is properly cited.

\begin{abstract}
Purpose: An open-label Phase I study of recombinant prime-boost poxviruses targeting CEA and MUC-I in patients with advanced pancreatic cancer was conducted to determine safety, tolerability and obtain preliminary data on immune response and survival.
\end{abstract}

Patients and methods: Ten patients with advanced pancreatic cancer were treated on a Phase I clinical trial. The vaccination regimen consisted of vaccinia virus expressing tumor antigens carcinoembryonic antigen (CEA) and mucin-I (MUC-I) with three costimulatory molecules B7.I, ICAM-I and LFA-3 (TRICOM) (PANVAC-V) and fowlpox virus expressing the same antigens and costimulatory molecules (PANVAC-F). Patients were primed with PANVAC-V followed by three booster vaccinations using PANVAC-F. Granulocyte-macrophage colony-stimulating factor (GMCSF) was used as a local adjuvant after each vaccination and for 3 consecutive days thereafter. Monthly booster vaccinations for up to 12 months were provided for patients without progressive disease. Peripheral blood was collected before, during and after vaccinations for immune analysis.

Results: The most common treatment-related adverse events were mild injection-site reactions. Antibody responses against vaccinia virus was observed in all 10 patients and antigen-specific $T$ cell responses were observed in 5 out of 8 evaluable patients (62.5\%). Median overall survival was 6.3 months and a significant increase in overall survival was noted in patients who generated anti CEAand/or MUC-I-specific immune responses compared with those who did not (I5.I vs 3.9 months, respectively; $P=.002$ ).

Conclusion: Poxvirus vaccination is safe, well tolerated, and capable of generating antigen-specific immune responses in patients with advanced pancreatic cancer.

\section{Introduction}

Pancreatic cancer is associated with a poor prognosis and high mortality rate. An estimated 37,170 new cases will be diagnosed in the United States in 2007 and 33,370 
patients will die from the disease [1]. The median overall survival rate in patients with unresectable or metastatic disease is typically 3-6 months [2]. Current treatment options for pancreatic cancer include surgery, chemotherapy, and radiotherapy but only complete surgical resection is associated with a favorable outcome $[1,3]$. Most patients with pancreatic cancer, however, have unresectable disease at presentation. Gemcitabine-based therapy is widely used in the treatment of advanced pancreatic cancer, although its benefits are primarily palliative with limited improvement in survival [4]. Thus, new therapeutic options are needed for patients with advanced pancreatic cancer.

There has been interest in using immunotherapy for pancreatic cancer based on the identification of mutated oncogenes, such as KRAS, altered tumor suppressor genes, such as TP53, CDKN2A, DPC4, BRCA2, and ERBB2, as well as over-expression of tumor-associated antigens, such as CEA and MUC-1, in pancreatic carcinoma cells [5]. The carcinoembryonic antigen (CEA) is an oncofetal antigen that is expressed at high levels in most pancreatic carcinomas. The mucin, MUC-1, is a highly glycosylated protein that is also overexpressed in many adenocarcinomas, including those of pancreatic origin. T cells from normal donors and cancer patients have been shown to recognize HLA-restricted epitopes derived from CEA and non-HLArestricted epitopes encoded by MUC-1 [6,7]. Targeting two distinct tumor antigens in a single vaccination regimen may induce better anti-tumor effects since the generation of polyclonal $\mathrm{T}$ cell responses may prevent tumor escape through antigen loss. Several preclinical models have demonstrated that the $\mathrm{T}$ cell dependent therapeutic effectiveness of using recombinant poxviruses expressing CEA or MUC-1 in both transplantable and transgenic model tumor systems [8-17].

The activation of $\mathrm{T}$ cells requires antigen-specific signals that are delivered through the $\mathrm{T}$ cell receptor after recognizing cognate peptides presented by major histocompatibility complexes (MHC) on antigen-presenting cells. In the face of weak antigenic stimuli, such as tumor antigens, successful activation of $\mathrm{T}$ cells also depends on costimulatory signals, which cooperate with $\mathrm{T}$ cell signaling to induce cytokine production and T-cell proliferation [17]. The co-expression of tumor antigens and costimulatory molecules within poxviruses represents a strategy that has demonstrated a significantly better anti-tumor effect in murine models [16,18-25]. The combination of B7.1, ICAM-1 and LFA-3 (TRICOM) appears to be particularly useful for both in vitro stimulation of $\mathrm{T}$ cells and for induction of tumor rejection in vivo $[18,19,24,26]$.

In addition to expression of costimulatory molecules in poxvirus vectors, the use of a heterologous prime-boost vaccination schedule with replicating and non-replicating vectors has shown superiority in generating tumor-specific $T$ cell responses in animal models [14]. Furthermore, pre- and clinical studies have shown that protection from malaria was enhanced when using a prime-boost vacciniafowlpox virus system expressing the $P$. falciparum circumsporozoite antigen (PfCSF) $[27,28]$. We have previously shown that prime-boost vaccination with a prostate specific antigen (PSA) vaccinia-fowlpox virus regimen induced a longer biochemical progression-free survival than vaccination with fowlpox-PSA virus alone [22]. In this study we tested the safety and feasibility of using poxviruses expressing CEA and MUC- 1 with TRICOM as a vaccine treatment for patients with advanced pancreatic carcinoma. A novel vaccinia virus vectors expressing both tumor antigens CEA and MUC-1, and costimulatory molecules TRICOM (PANVAC-V) was constructed and used to prime an initial T-cell response. Patients were then boosted with a non-replicating fowlpox virus expressing CEA, MUC-1 and TRICOM (PANVAC-F). The use of a prime-boost vaccination approach with vaccinia virus followed by fowlpox virus has been shown to increase the generation of $\mathrm{T}$ cell immunity to expressed antigens and may also improve therapeutic responses $[14,22,29,30]$. In order to further improve the clinical effectiveness of the vaccine, granulocyte-macrophage colony-stimulating factor (GM-CSF) was used as a vaccine adjuvant to enhance local antigen processing and presentation $[31,32]$. Thus, this trial incorporated four distinct strategies to increase the potency of anti-tumor immunity in pancreatic cancer patients - targeting multiple tumor antigens, expression of several T-cell costimulatory molecules, delivery using a heterologous prime-boost poxvirus system and inclusion of GM-CSF as a local adjuvant. We now report the safety and tolerability of this approach as well as immune responses and their correlation to overall patient survival.

\section{Patients and methods Patient eligibility}

The study populations comprised 10 patients $\geq 18$ years old who had been previously vaccinated against smallpox and had a histologically confirmed diagnosis of unresectable or metastatic pancreatic cancer; Karnofsky Performance Status (KPS) $\geq 80 \%$; and anticipated survival of $\geq 4$ months. Patients were required to use adequate contraceptives during the study and for 3 months after the final visit. Key exclusion criteria included: evidence of being immunocompromised; past or present diagnosis of autoimmune disease; steroid use within 28 days prior to signing consent; inability to avoid close contact with children $\leq 5$ years old, pregnant women, individuals with eczema or related skin conditions, and/or immunocompromised individuals for 3 weeks after the first vaccination; known egg or egg product allergy; positive for hepatitis B or C infection; compromised hematopoietic 
function; hepatic or renal dysfunction; significant cardiovascular abnormalities or other uncontrolled diseases or conditions; concurrent other malignancy, except nonmelanoma skin or in situ cervix carcinoma; prior malignancy that had not been curatively treated or that had recurred within 2 years; evidence of active, uncontrolled infection; completion of prior chemotherapy $<28$ days prior to the first vaccination; receipt of immunotherapy or biotherapy; and pregnancy or breastfeeding.

The study was approved by the individual Institutional Review Boards at each study site and was conducted in accordance with the Declaration of Helsinki. Written informed consent was obtained from all patients prior to study entry. An independent Data Safety Monitoring Board was established to ensure patient safety.

\section{Study design and treatment}

On Day 0, all patients were primed with rV-CEA/MUC-1/ TRICOM (PANVAC-V, $2 \times 10^{8} \mathrm{pfu}$ ). This was followed by booster doses of rF-CEA/MUC-1/TRICOM (PANVAC-F, 1 $\left.\times 10^{9} \mathrm{pfu}\right)$ on Days 14,28 , and 42 . Each vaccine was administered by subcutaneous injection. In addition, GM-CSF $100 \mu \mathrm{g}$ was administered at the vaccination site after each immunization and for 3 consecutive days thereafter. Patients were eligible to enroll in an optional extension phase provided they completed the core phase of 4 vaccinations and experienced disease stabilization with acceptable toxicity. For those patients enrolled in the extension phase, additional monthly boosts in combination with GM-CSF were provided for up to 12 months.

Adverse events were monitored throughout the trial by physical examinations, laboratory tests (chemistries and electrolytes, blood counts, coagulation parameters, hepatic enzymes and urinalysis), and vital sign measurements conducted on Days 0,14, 28, 42, and 70 in the core phase, and at each monthly boost visit in the extension phase. Twelve-lead ECGs were performed on Days 28 and 70 in the core phase, and at monthly boost visits from months 3 through 11 in the extension phase. Peripheral blood was collected for immune studies on Days 0, 14, 28,42 , and 70 in the core phase, and at each monthly boost visit in the extension phase.

A patient was withdrawn from the study if any of the following dose-limiting toxicities (DLT) were experienced: grade 2 asymptomatic bronchospasm or generalized urticaria or any other grade $\geq 3$ allergic reaction; grade $\geq 2$ autoimmune response; or any grade $\geq 3$ hematologic or nonhematologic reaction, including injection-site reaction.

\section{Vaccine preparation}

PANVAC-V and PANVAC-F vaccines were prepared from plaque-purified isolates from the Wyeth New York City Board of Health (New York, NY) for vaccinia vectors and from POXVAC-TC for fowlpox vectors. Virus for the vaccine was grown in primary chicken embryo dermal cells and formulated in phosphate-buffered saline containing $10 \%$ glycerol. Each vial of PANVAC-V contained $1.29 \times$ $10^{9} \mathrm{pfu} / 0.3 \mathrm{~mL}$, and PANVAC-F contained $8.93 \times 10^{9} \mathrm{pfu} /$ $0.3 \mathrm{~mL}$. All vials were stored at $-70^{\circ} \mathrm{C}$ or lower until the day of administration, at which time they were thawed at room temperature and prepared in a sterile manner.

\section{Evaluation of antibody responses}

Serum was collected as mentioned above, stored at $-20^{\circ} \mathrm{C}$ and used to determine anti-vaccinia virus, anti-fowlpox virus and anti-CEA antibody titers by standard ELISA, as previously described [33]. Briefly, 96-well plates were coated with the appropriate coating antigens overnight at $4^{\circ} \mathrm{C}$. Wells were blocked for $1 \mathrm{hr}$ at $37^{\circ} \mathrm{C}$ with $5 \%$ milk solution. Serum samples were diluted in $5 \%$ milk solution, with the starting sample at a 1:100 dilution and subsequent samples subjected to two-fold serial dilutions. The diluted test samples and assay positive and negative controls were added to the plates in duplicates. After incubation and washing, HRP-goat anti-human IgG was added and incubated for $1 \mathrm{hr}$ at $37^{\circ} \mathrm{C}$. Color was developed with Sure Blue TMB Microwell Peroxidase Substrate and absorbance was measured using a SpectraMax plate reader (Molecular Devices, CA). Antibody titers were defined as the mean optical density (O.D) of the test sera was $\geq 3$ fold the mean O.D of the negative control at 1:100 dilution. A positive antibody response due to vaccination was defined as $a \geq 2$ fold increase in the post-immunization titer as compared to the pre-immunization titer.

\section{Evaluation of $T$ cell responses}

PBMCs were separated from whole blood over a Ficoll gradient, and isolated PBMCs were frozen in liquid nitrogen until analysis. $\mathrm{T}$ cell responses were evaluated using a novel, research-grade, non-HLA-restricted cytokine secretion assay in all patients [34]. This assay compared the amount of IFN- $\gamma$ produced in response to monkey breast cancer cells (CMMT 110/C1) infected with PANVAC-F with that produced in response to cells infected with negative control viruses, TBC-F/TRICOM ${ }^{\mathrm{TM}}$ or PROSTVAC-F. Briefly, frozen PBMC were thawed and incubated in medium overnight at $37^{\circ} \mathrm{C}, 5 \% \mathrm{CO}_{2}$ prior to use. A CMMT 110/C1 cell line was infected with one of three different recombinant fowlpox viruses at a multiplicity of infection (MOI) of 40 pfu/cell: PANVAC-F, TBC-F/TRICOM (control fowlpox virus expressing TRICOM without CEA or MUC-1; data not shown) and PROSTVAC-F (control vector expressing PSA and TRICOM). On Day 2, each different infected CMMT 110/C1 preparation was mixed 
with patient PBMC at a ratio of 1:10 and co-cultured for 72 hours. At the end of the incubation period, supernatants were collected for IFN- $\gamma$ production by standard ELISA assay using ELISA kit (R \& D Systems). The limit of quantitation of IFN- $\gamma$ in the ELISA was $50 \mathrm{pg} / \mathrm{mL}$. When the number of viable patient PBMC permitted, the PBMC were also co-cultured with uninfected stimulator cells as an additional control. Under these conditions, IFN- $\gamma$ production was not observed (data not shown).

\section{Statistical methods}

Mean antibody titers against viral vectors, CEA and MUC1 were determined for all evaluable patients by ELISA. The development of a specific cell-mediated immune response to CEA and MUC-1 was determined by comparing the amount of IFN- $\gamma$ produced in response to monkey cells infected with PANVAC-F to the amount produced in response to cells infected with the negative control viruses, TBC-F/TRICOM or PROSTVAC-F. The Spearman correlation was used to investigate potential associations between response and clinical benefit. A $P$-value $<0.05$ was considered significant.

\section{Results}

\section{Patient characteristics}

Eleven patients were enrolled in the trial since one patient withdrew consent before completing the core phase and was replaced. All patients were evaluated for toxicity but only the 10 patients completing the study were use for immune analysis. Patient demographics and baseline characteristics are listed in Table 1. The majority of patients were Caucasian, with a mean age of approximately $57.9 \pm 9.6(43-74)$ years. All patients were heavily pretreated with $60 \%$ had two or more prior chemotherapy regimens. Over half of the patients had undergone surgical procedures for pancreatic cancer and the majority $(80 \%)$ had metastatic disease.

\section{Safety}

Toxicity was assessed using the National Cancer Institute Common Toxicity Criteria. The majority of adverse events were low grade injection site reactions or constitutional symptoms (Table 2). The most frequently encountered adverse events were grade 1 discomfort at the injection site (pain, erythema, edema; $n=5$ ), constitutional symptoms (fatigue, mylagias, headache; $n=9$ ), and gastrointestinal (nausea, vomiting, anorexia; $n=12$ ). There were no Grade 3 or greater adverse events related to vaccination. No patients in the trial discontinued because of an adverse event.

\section{Antibody responses}

Anti-poxvirus- and CEA-specific antibody responses were monitored by ELISA at each sampling time point throughout the trial and expressed as a titer (Table 3). All 10
Table I: Patient demographics

\begin{tabular}{lc}
\hline Characteristics & $\mathbf{N}=10$ \\
\hline Mean (range) age, years & $57.9 \pm 9.6(43-74)$ \\
Performance status*, $\mathrm{n}(\%)$ & \\
$80 \%$ & $4(40)$ \\
$90 \%$ & $3(30)$ \\
$100 \%$ & $3(30)$ \\
Sex, $\mathrm{n}(\%)$ & \\
Male & $7(70)$ \\
Female & $3(30)$ \\
Race, $\mathrm{n}(\%)$ & \\
Caucasian & $9(90)$ \\
Blacks/Asians & $\mathrm{I}(10)$ \\
Prior therapy, $\mathrm{n}$ (\%) & \\
Chemotherapy & \\
I prior regimen & $4(40)$ \\
$\geq 2$ prior regimens & $6(60)$ \\
Radiotherapy & $5(50)$ \\
Immunotherapy & $0(0)$ \\
Other & $\mathrm{I}(10)$ \\
HLA-A2 $\dagger$, n (\%) & \\
Positive & $3(30)$ \\
Negative & $7(70)$ \\
\hline
\end{tabular}

Abbreviation: $†$ HLA-A2, human leukocyte antigen-A2; * Karnofsky Performance Status (KPS)

patients developed antibody responses against vaccinia virus with 3 patients exhibiting titers $>1000$, although all patients had received prior smallpox vaccine. Seven of 10 patients $(70 \%)$ developed a significant increase in antifowlpox virus titers by day 70 with one patient exhibiting a 16 -fold increase 42 days after completing the assigned treatment. Similar to previous CEA-based vaccine trials, the anti-CEA antibody titers were much lower than antifowlpox virus titers $[15,35]$. Nonetheless, we detected an increase in anti-CEA antibody titers in 5 of $10(50 \%)$ patients following vaccination with one patient demonstrating persistent anti-CEA antibody titers up to 3 months after completing the core phase of the trial.

Table 2: Adverse events related to vaccination

\begin{tabular}{ccccc}
\hline Toxicity & $\begin{array}{c}\text { Total } \\
\text { Events } \\
(\mathbf{N}=\text { I 0) }\end{array}$ & Grade I & Grade 2 & Grade 3 \\
\hline $\begin{array}{c}\text { Injection site } \\
\text { reactions }\end{array}$ & 5 & 5 & 0 & 0 \\
$\begin{array}{c}\text { Fever or chills } \\
\text { Fatigue }\end{array}$ & 2 & 1 & 1 & 0 \\
Myalgia & 6 & 3 & 3 & 0 \\
Headache & 2 & 1 & 0 & 0 \\
Nausea & 4 & 0 & 2 & 0 \\
Vomiting & 3 & 2 & 2 & 0 \\
Anorexia & 5 & 1 & 2 & 0 \\
\hline
\end{tabular}


Table 3: Antibody responses to vaccine, fowlpox and CEA

\begin{tabular}{|c|c|c|c|c|}
\hline \multirow[t]{2}{*}{ Patient No. } & \multirow[t]{2}{*}{ Time point } & \multicolumn{3}{|l|}{ Titer } \\
\hline & & Anti-Vaccinia & Anti-Fowlpox & Anti-CEA \\
\hline \multirow[t]{7}{*}{$002-001$} & Day 0 & 1600 & 200 & $\mathrm{ND}^{\mathrm{a}}$ \\
\hline & Day 14 & 6400 & - & $<100$ \\
\hline & Day 28 & - & - & $<100$ \\
\hline & Day 42 & - & - & $<100$ \\
\hline & Day 70 & - & 3200 & $<100$ \\
\hline & Extension Phase Month $\mathrm{I}^{\mathrm{b}}$ & - & - & $<100$ \\
\hline & Extension Phase Month 2 & - & - & $<100$ \\
\hline \multirow[t]{5}{*}{$002-002$} & Day 0 & 1600 & $<100$ & ND \\
\hline & Day 14 & 3200 & - & $<100$ \\
\hline & Day 28 & - & - & $<100$ \\
\hline & Day 42 & - & - & $<100$ \\
\hline & Day 63 & - & 1600 & $<100$ \\
\hline \multirow{4}{*}{$002-003$} & Day 0 & 400 & $<100$ & ND \\
\hline & Day 14 & 1600 & - & $<100$ \\
\hline & Day 28 & - & $<100$ & $<100$ \\
\hline & Day 36 & - & - & ND \\
\hline \multirow{5}{*}{$002-005$} & Day 0 & 200 & $<100$ & ND \\
\hline & Day 14 & 800 & - & $<100$ \\
\hline & Day 28 & - & - & $<100$ \\
\hline & Day 42 & - & - & 100 \\
\hline & Day 70 & - & 400 & $<100$ \\
\hline \multirow[t]{7}{*}{$002-006$} & Day 0 & 200 & $<100$ & ND \\
\hline & Day 14 & 800 & - & $<100$ \\
\hline & Day 28 & - & - & $<100$ \\
\hline & Day 42 & - & - & 3200 \\
\hline & Day 70 & - & 800 & 800 \\
\hline & Extension Phase Month 2 & - & - & 800 \\
\hline & Extension Phase Month 3 & - & - & 400 \\
\hline \multirow[t]{13}{*}{$002-007$} & Day 0 & $<100$ & 200 & ND \\
\hline & Day 14 & 200 & - & $<100$ \\
\hline & Day 28 & - & - & $<100$ \\
\hline & Day 42 & - & - & 100 \\
\hline & Day 70 & - & 800 & 100 \\
\hline & Extension Phase Month 2 & - & - & $<100$ \\
\hline & Extension Phase Month 3 & - & - & $<100$ \\
\hline & Extension Phase Month 4 & - & - & $<100$ \\
\hline & Extension Phase Month 5 & - & - & $<100$ \\
\hline & Extension Phase Month 6 & - & - & $<100$ \\
\hline & Extension Phase Month 7 & - & - & $<100$ \\
\hline & Extension Phase Month 8 & - & - & $<100$ \\
\hline & Extension Phase Month 9 & - & - & $<100$ \\
\hline \multirow[t]{4}{*}{$001-008$} & Day 0 & 800 & $<100$ & ND \\
\hline & Day 14 & 6400 & - & $<100$ \\
\hline & Day 28 & - & - & $<100$ \\
\hline & Day 42 & - & 3200 & $<100$ \\
\hline \multirow[t]{3}{*}{$001-009$} & Day 0 & 800 & $<100$ & ND \\
\hline & Day 14 & 800 & - & $<100$ \\
\hline & Day 28 & - & $<100$ & $<100$ \\
\hline \multirow[t]{4}{*}{$001-010$} & Day 0 & 400 & $<100$ & ND \\
\hline & Day 14 & 1600 & - & $<100$ \\
\hline & Day 28 & - & - & $<100$ \\
\hline & Day 42 & - & 100 & 100 \\
\hline \multirow[t]{6}{*}{$001-011$} & Day 0 & 1600 & 100 & ND \\
\hline & Day 14 & 1600 & - & $<100$ \\
\hline & Day 28 & - & - & $<100$ \\
\hline & Day 42 & - & - & $<100$ \\
\hline & Day 70 & - & 800 & 200 \\
\hline & Extension Phase Month 2 & - & - & 100 \\
\hline
\end{tabular}

Bolded values indicate development of antibody response, which is defined as a 2-fold increase in titer of the post-immunization sample as compared to the corresponding negative control sample. aND: not determined. Because the time 0 sample is the negative control sample for the CEA ELISA, a titer cannot be assigned to this sample. bFor this patient, the sample collected approximately 2 weeks after the day 70 vaccination was labeled "Extension Phase Month I"; for all other patients, the sample collected one month after the day 70 vaccination was labeled "Extension Phase Month 2". 


\section{$T$ cell responses}

Antigen-specific immune responses were analyzed in eight patients using thawed PBMCs directly without any additional in vitro re-stimulation using a non-HLArestricted cytokine secretion assay. In this assay autologous T cells were co-cultured with CMMT 110/C1 cells infected with PANVAC-F or a PSA-TRICOM expressing fowlpox virus, PROSTVAC-F to determine responses to the CEA and MUC-1 antigens in the PANVAC-F vaccine. Among the 8 patients with enough cells for evaluation, five patients $(62.5 \%)$ developed a significant increase in antigen-specific (CEA or MUC-1) immune responses, which became detectable within 1-2 months of the first vaccination and generally increased with repeated boosting (Fig. 1). While no patients had detectable PANVAC-F specific $\mathrm{T}$ cell responses prior to PANVAC-F immunization, following prime-boost vaccination, positive responses were detected in 5 patients following PANVAC$\mathrm{F}$ boosting. Two additional patients showed an initial induction of PANVAC-F specific T cells but the responses were not seen at later time points; these two patients were not deemed to have statistically positive cellular responses. The tumor antigen-specific nature of the T cell responses was suggested by the increased recognition of PANVAC-F compared to PROSTVAC-F, although two patients did react to a lesser degree to PROSTVAC-F (Fig.
1) likely representing recognition of fowlpox virus antigens.

\section{Immune response and overall survival}

The median overall survival was 6.3 months (range, 1.5-21.1 months; Fig. 2). Of note was the 1 year survival rate of $30 \%$, although this trial was not designed to detect clinical responses. To explore whether there was an association between $\mathrm{T}$ cell response and clinical outcome we compared the overall survival of the five patients who demonstrated an increase in $\mathrm{T}$ cell response to the five who did not (Fig. 3). While these results must be interpreted cautiously, we did observe a significant increase in overall survival in the patients who generated vaccine-specific $\mathrm{T}$ cell responses compared to those without $\mathrm{T}$ cell reactivity (median survival 15.1 vs. 3.9 months, respectively; $P=.002)$.

\section{Discussion}

This Phase 1 clinical trial provides evidence that primeboost vaccination with recombinant vaccinia and fowlpox viral vectors expressing CEA, MUC-1 and the TRICOM costimulatory molecules administered with local GM-CSF is safe and well tolerated. The most common treatmentrelated adverse events were mild injection-site reactions and no patients discontinued vaccination due to treat-

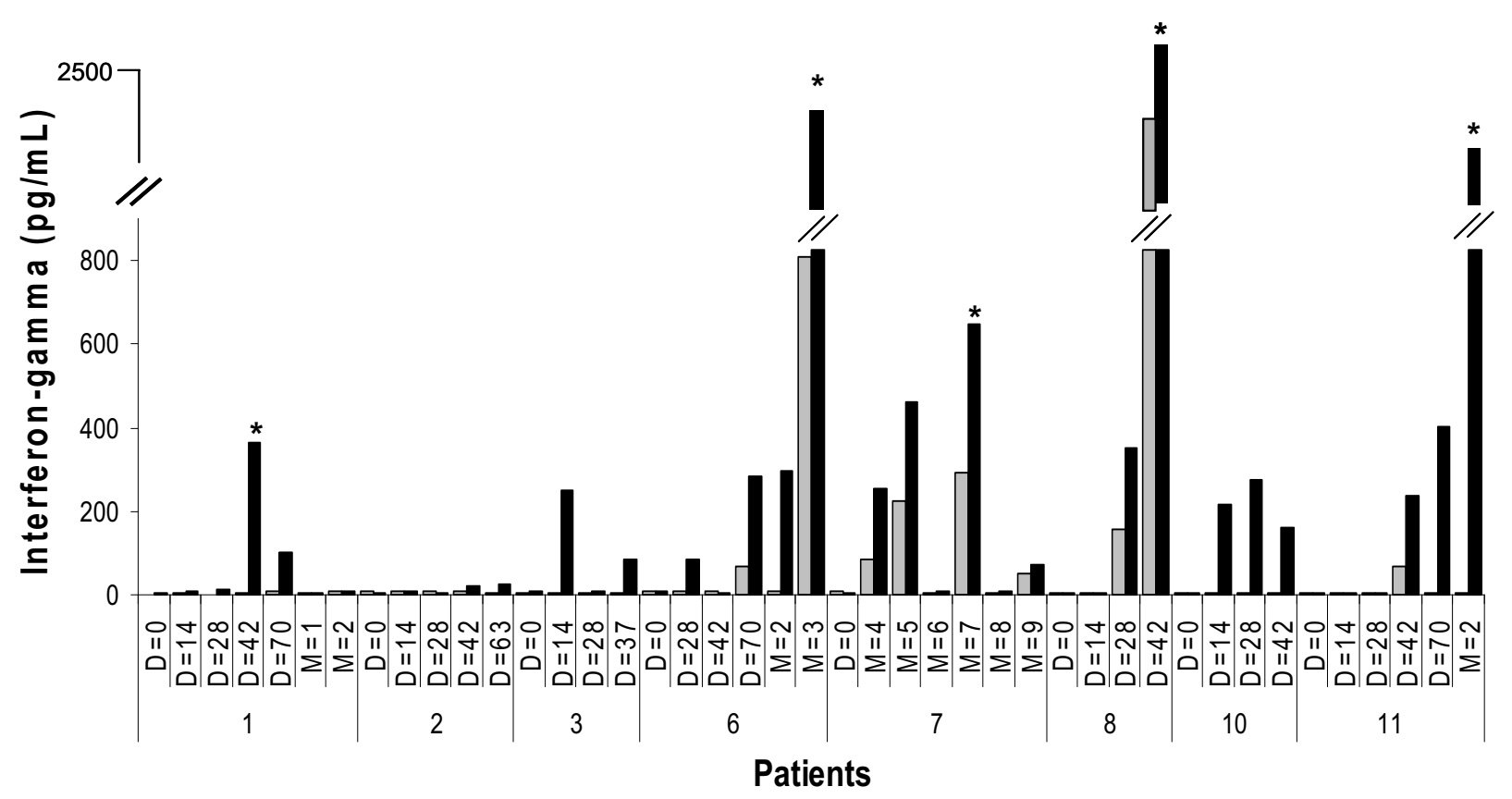

Figure I

Cellular immune responses in vaccinated patients. Peripheral blood mononuclear cells were collected at the indicated day (D) or month (M) following initial immunization. Peripheral blood mononuclear cells were co-cultured with $\mathrm{CMMT} \mathrm{II0/CI} \mathrm{cells}$ infected with a multiplicity of infection (MOI) of 40 plaque-forming units (pfu)/cell of fowlpox virus expressing CEA, MUC-I and TRICOM (Black), or fowlpox virus expressing PSA and TRICOM; (Grey). *Denotes two-fold increase of CEA/MUC-I-specific T cell response compared to PSA control. 


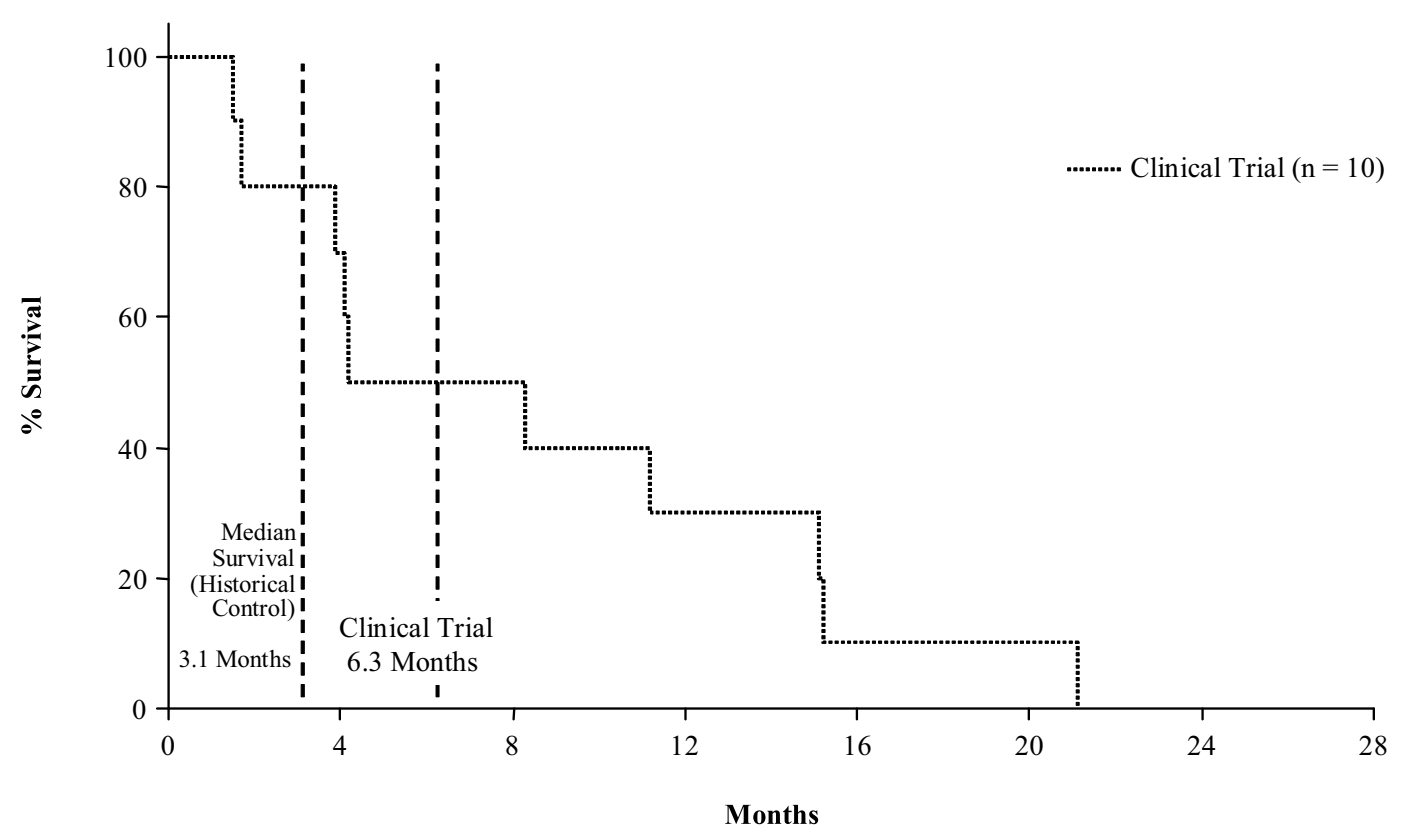

\section{Figure 2}

Overall survival of patients enrolled in trial compared with historical control. Median overall survival $=6.30$ months (Trial), and 3.I months (control).

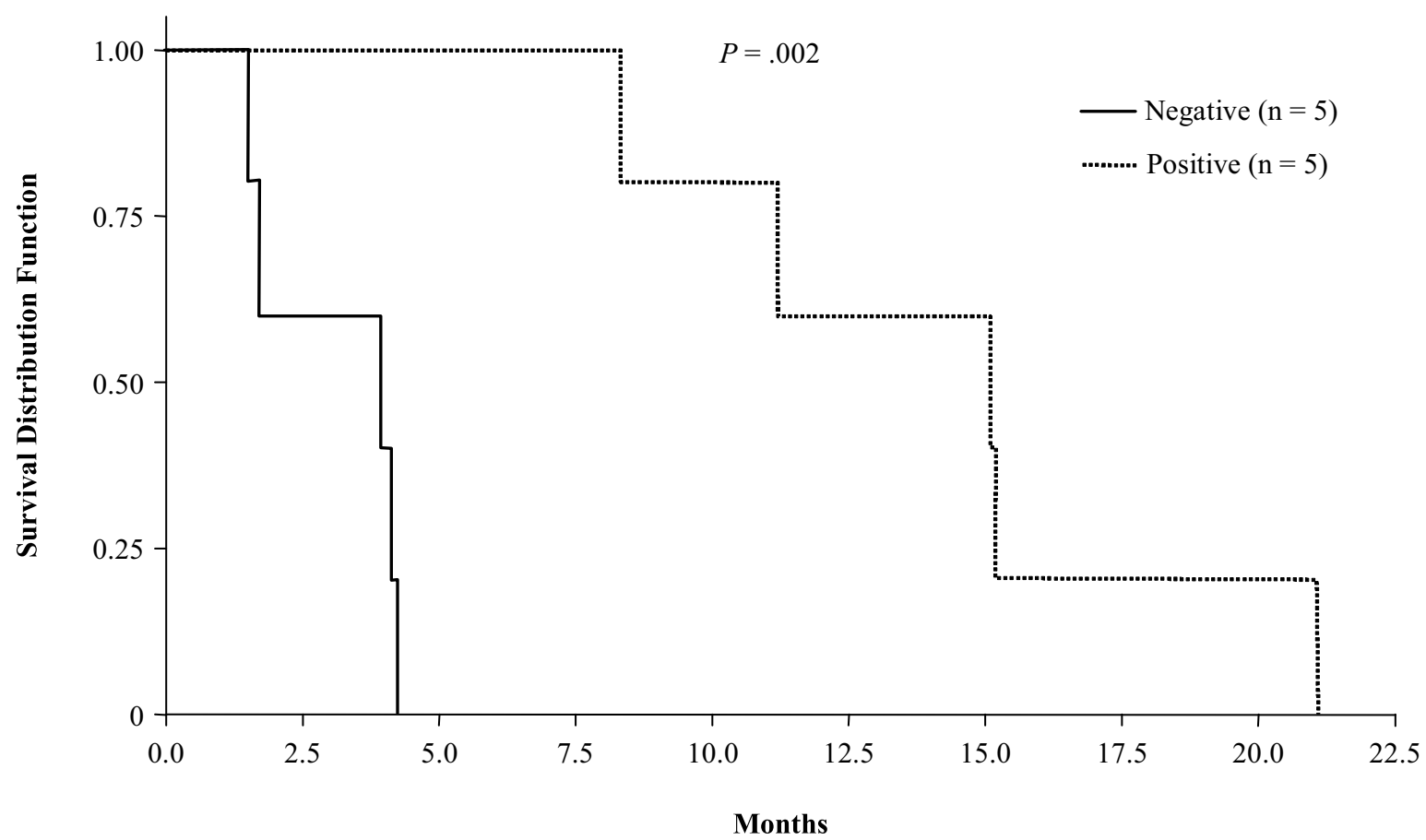

\section{Figure 3}

Overall survival of patients enrolled in the study. Positive indicates patients who had evidence of the development of a carcinoembryonic antigen (CEA)- and/or mucin-I (MUC-I)-specific immune response. Negative indicates patients who did not develop an immune response $(n=3)$ or who were not assayed $(n=2)$. 
ment-related adverse events. The vaccination regimen was also effective in generating antibody responses against the viral vectors and five patients generated an increase in anti-CEA antibody titers following vaccination. In agreement with other CEA-based vaccine trials we noted a relatively low titer of anti-CEA antibodies which may be related to the low immunogenicity of CEA or the presence of circulating CEA antigen-antibody complexes [33]. Nonetheless, even after subtracting background activity, we could still detect an increase in titers in five patients with one showing a dramatic increase at day 42 , which remained elevated for at least 3 months. All patients developed anti-vaccinia antibody titers and some patients had pre-existing titers presumably related to prior smallpox vaccination, since immunity is known to persist for decades, in some cases [35]. Whether these high titers interfere with subsequent induction of $\mathrm{T}$ cell responses cannot be determined from our study due to the limited number of patients. In contrast, antibody titers against fowlpox virus were lower and this is consistent with the non-replicative nature of this virus.

We utilized a novel cytokine release assay using recombinant virus-infected CMMT 110/C1 cells as targets. This assay has several advantages for monitoring viral vaccine trials. The CMMT 110/C1 cell line represents a potentially useful alternative APC for antigen-presentation when autologous DC are limited or when multiple antigens need to be tested. These cells are highly permissive to poxvirus infection and human T cells are highly cross-reactive with rhesus monkey cells. This is due, in part to the evolutionary conservation of MHC-DR/peptide/T cell interactions between humans and rhesus monkeys [36,37]. Furthermore, Geluk et al. demonstrated that human $\mathrm{T}$ cells could proliferate in response to human hsp65 $5_{\mathrm{p} 3-13}$ peptide when presented by rhesus APC $M h c$-DRB1*03 [38]. In an experimental autoimmune encephalitis (EAE) model, human whole myelin basic protein (MBP) or purified MBP induced pathologic CNS lesions in rhesus monkeys presumably mediated by rhesus $\mathrm{CD}^{+} \mathrm{T}$ cells [39]. These studies also suggested that the amplitude of the T cell response was comparable to that induced by human APC and confirmed that rhesus APC can efficiently process human antigens and provide co-stimulatory signals to human T cells. The permissiveness of the CMMT 110/C1 cell to poxvirus infection allows evaluation of $\mathrm{T}$ cell response against a full range of putative antigenic epitopes encoded by tumor antigens within the recombinant fowlpox virus vector.

In the current trial, we observed 5 of $8(62.5 \%)$ patients in the study developed evidence of increased antigen-specific $\mathrm{T}$ cells within 2 months of vaccination and these persisted during the booster phase of the clinical trial. Although two patients also developed detectable levels of IFN- $\gamma$
$(>200 \mathrm{pg} / \mathrm{ml})$ at one or more time points, they were not considered to have developed a significant responses to PANVAC-VF based on our validation cutoff levels. Nonetheless, this level of $\mathrm{T}$ cell response compares favorably with other trials of CEA and MUC-1-based vaccines $[15,40]$. Patients also developed $T$ cell responses against fowlpox virus, although at much lower frequencies (Fig. 1 ). The data in our trial represents a small sample size, but these encouraging results suggest that our assay may be promising for monitoring other studies using viral vaccines.

Patients with pancreatic cancer may exhibit signs of active systemic immunosuppression due to prior chemotherapy and radiotherapy. Several studies have observed that cytotoxic $\mathrm{CD}^{+} \mathrm{T}$ cells do not reach the tumor microenvironment in significant numbers because most of the cells aggregate in peritumoral tissues distant from the tumor cells $[41,42]$. The inactivation of $\mathrm{T}$ cells due to down-regulation of the adhesion molecule ligand $\left(\mathrm{CD}_{103}{ }^{+}\right)$and overexpression of immunosuppressive cytokines (TGF- $\beta$ ) observed in pancreatic cancer cells provide further evidence of immunosuppression in this population [43-45]. In addition, many patients with pancreatic cancer are heavily pretreated with chemotherapy, which may contribute to the highly suppressive nature of this patient population. In fact, all of our patients had been pretreated with the majority having two or more prior chemotherapy regimens. Thus, the pancreatic cancer patient with advanced disease may represent a particularly difficult population to target with vaccines. Nonetheless, the detection of CEA-specific T cells in $62.5 \%$ of the vaccinated patients in this study suggest that vaccines would be more effective in induction of immunity in less immune suppressive environment as in patients with less advanced disease.

We also utilized local GM-CSF as a vaccine adjuvant in this trial, which is thought to promote local dendritic cell accumulation and presentation of virally-expressed antigens. This may have also played a role in improving the level of vaccine-specific immunity observe in our trial as other studies of irradiated GM-CSF-secreting allogeneic pancreatic tumor cell vaccines have also shown potent immune responses and potential therapeutic activity in early phase clinical trials [46]. Previous studies in patients with pancreatic cancer suggested that survival was closely correlated with the density of $\mathrm{CD}^{+} \mathrm{T}$ cells within the tumor microenvironment [47]. More recently clinical investigation with poxviruses has similarly suggested an association between the generation of CEA-specific immunity and survival. Marshall and colleagues observed a similar effect and demonstrated increased progressionfree survival in patients with CEA-expressing tumors who developed CEA-specific T cell responses following vacci- 
nation with recombinant poxviruses expressing CEA and costimulatory molecules [48]. The preliminary data from our Phase 1 clinical trial found a similar survival benefit in patients who developed CEA-specific T cell immunity and survival (see Figure 3 ). The median overall survival was nearly 4 -fold longer in patients who exhibited evidence of an increased CEA-specific $\mathrm{T}$ cell response.

The Phase 1 clinical trial reported here establishes the preliminary safety and efficacy profiles of targeted cancer immunotherapy using a prime-boost vaccinia/fowl poxvirus vaccine regimen in patients with advanced pancreatic cancer. All patients developed anti-viral antibody titers and five patients developed anti-CEA antibody titers after vaccination. We also observed an increase in tumor antigen-specific $\mathrm{T}$ cell responses in $62.5 \%$ of the patients using a modified IFN- $\gamma$ release assay with another two patients showing a non-significant increase. Importantly, we also documented an association between these $T$ cell responses and overall survival, although this trial was not designed to detect such responses and therefore these results should be viewed as exploratory. In conclusion, vaccination with recombinant poxviruses generates meaningful antigenspecific immune responses even in heavily pre-treated pancreatic cancer patients. Future studies need to evaluate vaccine therapy in patients with less advanced disease, in those with less prior exposure to chemotherapy, and in combination with therapeutic strategies aimed at blocking immunosuppressive mechanisms. Such studies should help define the role of vaccine therapy for patients with pancreatic cancer.

\section{Authors' contributions}

HLK conducted the clinical trial and contributed to the data analysis and manuscript preparation. SK-S contributed to the immunological analysis and manuscript preparation. KM conducted the immune assays. GD contributed to the screening and treatment of clinical study subjects. JM contributed to the data collection, entry and regulatory management of the clinical trial. KS contributed to the data analysis and manuscript preparation. DK contributed to the immune assay analysis and data interpretation. JM conducted the clinical trial at his institution and contributed to data analysis and manuscript preparation. All authors read and approved the final manuscript.

\section{Acknowledgements}

Financial support for this study was provided by Therion Biologics, Cambridge, MA.

Previous Publication: This is an original work that has not been submitted simultaneously for publication elsewhere. Data from this study were presented in part at:
- 40 th Annual Meeting of the American Society of Clinical Oncology, June5-8, 2004, New Orleans, LA (poster presentation)

4 I $^{\text {st }}$ Annual Meeting of the American Society of Clinical Oncology, May 13-17, 2005, Orlando, FL (poster presentation)

\section{References}

I. American Cancer Society: Cancer Facts \& Figures 2006: Atlanta: American Cancer Society. 2006 [http://www.can cer.org]. Accessed May 8, 2006.

2. Li D, Xie K, Wolff R, Abbruzzese JL: Pancreatic cancer. Lancet 2004, 363:1049-1057.

3. Ko AH, Dito E, Schillinger B, Venook AP, Bergsland EK, Tempero MA: Phase II study of fixed dose rate gemcitabine with cisplatin for metastatic adenocarcinoma of the pancreas. I Clin Oncol 2006, 24:379-385.

4. Tempero M, Alasadi R, Behrman S: Clinical practice guidelines in oncology. Pancreatic Adenocarcinoma. National Comprehensive Cancer Network 2006 [http://www.nccn.org].

5. Laheru D, Jaffee EM: Immunotherapy for pancreatic cancer science driving clinical progress. Nat Rev Cancer 2005, 5:459-467.

6. Tsang KY, Palena C, Gulley J, Arlen P, Schlom J: A human cytotoxic T-lymphocyte epitope and its agonist epitope from the nonvariable number of tandem repeat sequence of MUC-I. Clin Cancer Res 2004, 10:2139-2149.

7. Finn OJ, Jerome KR, Henderson RA, Pecher G, Domenech N, Magarian-Blander J, Barratt-Boyes SM: MUC-I epithelial tumor mucinbased immunity and cancer vaccines. Immunol Rev 1995, 145:6I-89.

8. Aarts WM, Schlom J, Hodge JW: Vector-based vaccine/cytokine combination therapy to enhance induction of immune responses to a self-antigen and antitumor activity. Cancer Res 2002, 62:5770-5777.

9. Tsang KY, Palena C, Yokokawa J, Arlen PM, Gulley JL, Mazzara GP, Gritz L, Gomez Yafal A, Ogueta S, Greenhalgh P, et al.: Analyses of Recombinant Vaccinia and Fowlpox Vaccine Vectors Expressing Transgenes for Two Human Tumor Antigens and Three Human Costimulatory Molecules. Clin Cancer Res 2005, I I:1597-1607.

10. Pantuck AJ, van Ophoven A, Gitlitz BJ, Tso CL, Acres B, Squiban P, Ross ME, Belldegrun AS, Figlin RA: Phase I trial of antigen-specific gene therapy using a recombinant vaccinia virus encoding MUC-I and IL-2 in MUC-I-positive patients with advanced prostate cancer. J Immunother 2004, 27:240-253.

II. Bu D, Domenech N, Lewis J, Taylor-Papadimitriou J, Finn OJ: Recombinant vaccinia mucin vector: in vitro analysis of expression of tumor-associated epitopes for antibody and human cytotoxic T-cell recognition. J Immunother 1993, 14:127-135.

12. Balloul JM, Acres RB, Geist M, Dott K, Stefani L, Schmitt D, Drillien R, Spehner D, McKenzie I, Xing PX, et al.: Recombinant MUC I vaccinia virus: a potential vector for immunotherapy of breast cancer. Cell Mol Biol (Noisy-le-grand) 1994, 40(Suppl I):49-59.

13. Akagi J, Nakagawa K, Egami H, Ogawa M: Induction of HLA-unrestricted and HLA-class-II-restricted cytotoxic $T$ lymphocytes against MUC-I from patients with colorectal carcinomas using recombinant MUC-I vaccinia virus. Cancer Immunol Immunother 1998, 47:21-3I.

14. Hodge JW, McLaughlin JP, Kantor JA, Schlom J: Diversified prime and boost protocols using recombinant vaccinia virus and recombinant non-replicating avian pox virus to enhance $T$ cell immunity and antitumor responses. Vaccine 1997, 15:759-768.

15. Zhu MZ, Marshall J, Cole D, Schlom J, Tsang KY: Specific cytolytic T-cell responses to human CEA from patients immunized with recombinant avipox-CEA vaccine. Clin Cancer Res 2000, 6:24-33.

16. Kudo-Saito C, Hodge JW, Kwak H, Kim-Schulze S, Schlom J, Kaufman HL: 4-I BB ligand enhances tumor-specific immunity of poxvirus vaccines. Vaccine 2006, 24:4975-4986.

17. Croft M, Dubey C: Accessory molecule and costimulation requirements for CD4 T cell response. Crit Rev Immunol I997, 17:89-118. 
18. Kaufman HL, Cohen S, Cheung K, DeRaffele G, Mitcham J, Moroziewicz D, Schlom J, Hesdorffer C: Local delivery of vaccinia virus expressing multiple costimulatory molecules for the treatment of established tumors. Hum Gene Ther 2006, 17:239-244.

19. Hodge JW, Greiner JW, Tsang KY, Sabzevari H, Kudo-Saito C, Grosenbach DW, Gulley JL, Arlen PM, Marshall JL, Panicali D, Schlom $\mathrm{J}$ : Costimulatory molecules as adjuvants for immunotherapy. Front Biosci 2006, I I:788-803.

20. Dipaola R, Plante M, Kaufman H, Petrylak D, Israeli R, Lattime E, Manson K, Schuetz T: A Phase I Trial of Pox PSA vaccines (PROSTVAC(R)-VF) with B7-I, ICAM-I, and LFA-3 co-stimulatory molecules (TRICOMtrade mark) in Patients with Prostate Cancer. J Transl Med 2006, 4:I-5.

21. Kaufman HL, DeRaffele G, Mitcham J, Moroziewicz D, Cohen SM, Hurst-Wicker KS, Cheung K, Lee DS, Divito J, Voulo M, et al.: Targeting the local tumor microenvironment with vaccinia virus expressing B7.I for the treatment of melanoma. J Clin Invest 2005, II 5: $1903-1912$

22. Kaufman HL, Wang W, Manola J, DiPaola RS, Ko YJ, Sweeney C, Whiteside TL, Schlom J, Wilding G, Weiner LM: Phase II randomized study of vaccine treatment of advanced prostate cancer (E7897): a trial of the Eastern Cooperative Oncology Group. J Clin Oncol 2004, 22:2122-2। 32.

23. Shankar P, Schlom J, Hodge J: Enhanced activation of rhesus $\mathbf{T}$ cells by vectors endcoding a triad of costimulatory molecules (B7-I, ICAM-I, LFA-3). Vaccine 2002, 20:744-755.

24. Hodge J, Sabzevari H, Yafal A, Gritz L, Lorenz M, Schlom J: A triad of costimulatory molecules synergize to amplify T-cell activation. Cancer Res 1999, 59:5800-5807.

25. Hodge J, Abrams S, Schlom J, Kantor J: Induction of antitumor immunity by recombinant vaccinia viruses expressing B7or B7-2 costimulatory molecules. Cancer Res 1994, 54:5552-5555.

26. Shankar P, Schlom J, Hodge JW: Enhanced activation of rhesus $\mathbf{T}$ cells by vectors encoding a triad of costimulatory molecules (B7-I, ICAM-I, LFA-3). Vaccine 200I, 20:744-755.

27. Wang R, Epstein J, Baraceros FM, Gorak EJ, Charoenvit Y, Carucci DJ, Hedstrom RC, Rahardjo N, Gay T, Hobart P, et al: Induction of CD4+ $T$ cell-dependent CD8+ type I responses in humans by a malaria DNA vaccine. Proc Natl Acad Sci USA 200I, 98:10817-10822.

28. Sedegah M, Jones TR, Kaur M, Hedstrom R, Hobart P, Tine JA, Hoffman SL: Boosting with recombinant vaccinia increases immunogenicity and protective efficacy of malaria DNA vaccine. Proc Natl Acad Sci USA 1998, 95:7648-7653.

29. Hodge JW, Poole DJ, Aarts WM, Gomez Yafal A, Gritz L, Schlom J: Modified vaccinia virus ankara recombinants are as potent as vaccinia recombinants in diversified prime and boost vaccine regimens to elicit therapeutic antitumor responses. Cancer Res 2003, 63:7942-7949.

30. Santra S, Sun Y, Parvani JG, Philippon V, Wyand MS, Manson K, Gomez-Yafal A, Mazzara G, Panicali D, Markham PD, et al.: Heterologous Prime/Boost Immunization of Rhesus Monkeys by Using Diverse Poxvirus Vectors. J Virol 2007, 8 I:8563-8570.

31. Dranoff G, Jaffee E, Lazenby A, Golumbek P, Levitsky H, Brose K, Jackson V, Hamada H, Pardoll D, Mulligan RC: Vaccination with Irradiated Tumor Cells Engineered to Secrete Murine Granulocyte-Macrophage Colony-Stimulating Factor Stimulates Potent, Specific, and Long-Lasting Anti-Tumor Immunity. Proc Natl Acad Sci USA 1993, 90:3539-3543.

32. Morrissey PJ, Bressler L, Park LS, Alpert A, Gillis S: Granulocytemacrophage colony-stimulating factor augments the primary antibody response by enhancing the function of antigen-presenting cells. J Immunol 1987, I39: I I I- I II9.

33. Conry RM, Allen KO, Lee S-w, Moore SE, Shaw DR, LoBuglio AF: Human Autoantibodies to Carcinoembryonic Antigen (CEA) Induced by a Vaccinia-CEA Vaccine. Clin Cancer Res 2000, 6:34-41.

34. Manson K, Dolan K, Marshall J: A novel non-HLA restricted cellular immune assay for monitoring patient response to targeted immunotherapeutics. Proc Am Soc Clin Oncol 2006, 24(Suppl I8S):2567.

35. Eichner M: Analysis of Historical Data Suggests Long-lasting Protective Effects of Smallpox Vaccination. Am J Epidemiol 2003, I 58:717-723.
36. Slierendregt BL, van Noort JT, Bakas RM, Otting N, Jonker M, Bontrop RE: Evolutionary stability of transspecies major histocompatibility complex class II DRB lineages in humans and rhesus monkeys. Hum Immunol 1992, 35:29-39.

37. Otting N, Bontrop RE: Evolution of the major histocompatibility complex DPAI locus in primates. Hum Immunol 1995, 42: 184- 187

38. Geluk A, Elferink DG, Slierendregt BL, van Meijgaarden KE, de Vries RR, Ottenhoff TH, Bontrop RE: Evolutionary conservation of major histocompatibility complex-DR/peptide/T cell interactions in primates. J Exp Med 1993, 177:979-987.

39. 't Hart BA, Bauer J, Brok HP, Amor S: Non-human primate models of experimental autoimmune encephalomyelitis: Variations on a theme. J Neuroimmunol 2005, I68:I-12.

40. Marshall JL, Hoyer RJ, Toomey MA, Faraguna K, Chang P, Richmond E, Pedicano JE, Gehan E, Peck RA, Arlen P, et al.: Phase I study in advanced cancer patients of a diversified prime-and-boost vaccination protocol using recombinant vaccinia virus and recombinant nonreplicating avipox virus to elicit anti-carcinoembryonic antigen immune responses. J Clin Oncol 2000, 18:3964-3973.

4I. Chan A, Lockhart D, von Bernstorff W, Spanjaard R, Joo H-G, Eberlein T, Goedegebuure P: Soluble MUCI secreted by human epithelial cancer cells mediates immune suppression by blocking T-cell activation. Int J Cancer 1999, 82:72I-726.

42. Ungefroren $\mathrm{H}$, Voss M, Bernstorff WV, Schmid A, Kremer B, Kalthoff $\mathrm{H}$ : Immunological Escape Mechanisms in Pancreatic Carcinoma. Ann NYAcad Sci 1999, 880:243-25I.

43. Feng $Y$, Wang D, Yuan R, Parker CM, Farber DL, Hadley GA: CD I 03 Expression Is Required for Destruction of Pancreatic Islet Allografts by CD8+ T Cells. J Exp Med 2002, 196:877-886.

44. Gaspar NJ, Li L, Kapoun AM, Medicherla S, Reddy M, Li G, O'Young G, Quon D, Henson M, Damm DL, et al.: Inhibition of Transforming Growth Factor beta Signaling Reduces Pancreatic Adenocarcinoma Growth and Invasiveness. Mol Pharmacol 2007, 72:152-16|

45. French JJ, Cresswell J, Wong W, Seymour K, Charnley RM, Kirby J: T cell adhesion and cytolysis of pancreatic cancer cells: a role for E-cadherin in immunotherapy? Br J Cancer 2002, 87:1034-104I.

46. Jaffee EM, Hruban RH, Biedrzycki B, Laheru D, Schepers K, Sauter PR, Goemann M, Coleman J, Grochow L, Donehower RC, et al.: Novel Allogeneic Granulocyte-Macrophage Colony-Stimulating Factor-Secreting Tumor Vaccine for Pancreatic Cancer: A Phase I Trial of Safety and Immune Activation. J Clin Oncol 200I, 19:145-I56.

47. Ryschich E, Notzel T, Hinz U, Autschbach F, Ferguson J, Simon I, Weitz J, Frohlich B, Klar E, Buchler MW, Schmidt J: Control of Tcell-mediated immune response by HLA class $I$ in human pancreatic carcinoma. Clin Cancer Res 2005, I I:498-504.

48. Marshall JL, Gulley JL, Arlen PM, Beetham PK, Tsang K-Y, Slack R, Hodge JW, Doren S, Grosenbach DW, Hwang J, et al.: Phase I Study of Sequential Vaccinations With Fowlpox-CEA(6D)-TRICOM Alone and Sequentially With Vaccinia-CEA(6D)-TRICOM, With and Without Granulocyte-Macrophage ColonyStimulating Factor, in Patients With Carcinoembryonic Antigen-Expressing Carcinomas. J Clin Oncol 2005, 23:720-731.

Publish with Bio Med Central and every scientist can read your work free of charge

"BioMed Central will be the most significant development for disseminating the results of biomedical research in our lifetime. "

Sir Paul Nurse, Cancer Research UK

Your research papers will be:

- available free of charge to the entire biomedical community

- peer reviewed and published immediately upon acceptance

- cited in PubMed and archived on PubMed Central

- yours - you keep the copyright 